\title{
O conto Adão e Eva, de Machado de Assis, numa correlação com a definição de Paul Tillich da Bíblia
}

\author{
Ivna Maia Fuchigami*
}

\section{RESUMO}

O presente artigo tem por objeto apontar as possíveis aproximações entre o conto machadiano, Adão e Eva, com o pensamento tillichiano sobre sua definição da Bíblia. Machado de Assis, considerado inadvertidamente como um cético radical ou uma pessoa avessa à Religião, desenvolve suas reflexões religiosas ora de forma explícita ora de forma implícita. Representando artisticamente sua cosmovisão, o escritor extrai do cotidiano temas banais para refletirmos teologicamente, sem colocar deliberadamente as questões em termos propriamente religiosos, mas criando espaços vazios que levam a uma relação texto-leitor em que este é estimulado a interagir com o texto e a fazer pontes entre o dito e o não dito. O teológico em Machado de Assis não se sobrepõe ao literário, mas ambos se expressam de forma literária.

Palavras-chave:Machado de Assis - Paul Tillich - Literatura - Teologia - Religião - Bíblia.

\section{AD $\tilde{O}$ E EVA SHORT STORY BY MACHADO DE ASSIS, IN A COR- RELATION WITH PAUL TILLICH'S DEFINITION OF THE BIBLE}

\begin{abstract}
The present article intends to point out some possible proximities betweenAdão e Eva short story by Machado de Assis with Paul Tillich's thoughts about the Bible. Inaccuratelyconsidered as a radical skeptical writer or as someone against Religion, Machado de Assis develops his religious considerations either in a explicit or in a implicit way. By representing his artistisc-like cosmovision, the writer takes from daily life ordinary topics in order to think theologically without pointing out the themes in religious terms, but by creating empty spaces that lead to a relationship where text encourages the reader to interact with the text
\end{abstract}


and to set up bridges between the told and the untold. The theological aspect in Machado de Assis does not surpass literature, but both are expressed in a literary way.

Keywords: Machado de Assis - Paul Tillich - Literature - Theology Religion - Bible.

\section{Introdução}

O presente artigo parte de dois textos básicos: a apresentação da edição brasileira do livro Teologia da Cultura, de Paul Tillich, edição de 2009, com tradução de Jaci Maraschin, pela Fonte Editorial, e o conto Adão e Eva, de Machado de Assis, publicado em Várias Histórias, em 1896.

Consoante Tillich (2009), a teologia deve refletir a presença de Deus e sua alteridade e será a partir desta reflexão que se inserem as três conceituações que alicerçam o pensamento do teólogo e filósofo: a correlação da mensagem com a situação existencial; o aspecto simbólico da linguagem religiosa que evita a apropriação, dogmatismo e idolatria; o princípio protestante, que define a justiça como algo que não se encontra limitado ao campo denominacional, mas exprime uma busca humana.

Cabe, portanto, à teologia correlacionar a presença de Deus e sua alteridade. Para Tillich (2009), a Bíblia consistiria nessas duas experiências. E aqui reproduzimos um trecho do livro: "A Bíblia não é um livro caído do céu, um código sagrado, ou uma declaração doutrinal da fé. É a soma das experiências e dos encontros que pessoas no Antigo Testamento e depois no Novo Testamento tiveram com Deus" (p. 24).

Assim sendo, para Tillich "a essência da Bíblia é o testemunho de experiências e encontros"(Ibid.), que são expressões do que ocorreu em determinadas geografias e traduzem vivências culturais definidas. Por não serem diretamente acessíveis à nossa experiência, carecem de uma correspondência formal.

Nesta correlação, um elemento não elimina a existência do outro. Por conseguinte, a reflexão teológica desenvolve-se entre a verdade da mensagem cristã e a interpretação dessa verdade. Tal interpretação 
deve levar em consideração a situação em que se encontra o destinatário da mensagem. Por situação, Tillich se refere às formas científicas e artísticas, econômicas, políticas e éticas em que indivíduos e grupos expressam sua interpretação a respeito da existência.

Em tal perspectiva, segundo a qual a Bíblia é a soma das experiências e dos encontros que pessoas no Antigo Testamento e no Novo Testamento tiveram com Deus, e não um código sagrado ou uma declaração doutrinal da fé, é que surgiu a possibilidade de analisar o conto Adão e Eva, de Machado de Assis, em cuja obra sobejam personagens bíblicos e expressões religiosas (só neste conto, podemos mencionar paraíso terrestre, Pentateuco, Escritura, Deus, Diabo, Cruz, Tinhoso, Adão e Eva, Bem e Mal, Maria de Nazaré, Gabriel, anjos).

Ao tomar conhecimento da reflexão de Tillich como sendo a Bíblia uma soma das experiências e dos encontros, e, sobretudo, ao levar em conta que é importante a situação em que se encontra o destinatário da mensagem, percebi que seria possível unir os dois conceitos tillichianos com a maneira como Machado de Assis coloca o leitor diante de um texto que inverte a ordem com que geralmente o leitor da Bíblia conhece o Gênese.

Machado de Assis frequentemente se referiu à Bíblia e à religião. Aliás, no texto de Davi da Silva Oliveira, o escritor foi o mais bíblico dos autores da literatura brasileira. Só para darmos um exemplo, entre as obras da segunda fase, Dom Casmurro é o romance em que mais sobejam as referências à religiosidade, à vocação eclesiástica, aos interesses pouco cristãos, à fé. Sem falar na relação indivíduo-Deus, empregando um tom leve, mas cheio de malícia, ironia, Machado de Assis vai sugerindo o pouco que as pessoas fazem de sua religiosidade e, quando resolvem levar Deus em consideração, é numa relação de um Deus vingativo e cruel, como é o que ocorre com dona Glória, mãe de Bentinho, que promete enviar o filho ao seminário como forma de pagamento de uma promessa. Essa frequente referência ao Livro Sagrado é porque o escritor tinha profundo conhecimento do mesmo e, em vários de seus poemas, como A morte no Calvário, Monte Alverne, entre outros, ele expressa seu profundo respeito a Jesus e escreve que as pessoas deveriam seguir os passos do Filho de Deus. Ainda sobre o assunto, Jean-Michel Massa, um dos maiores estudiosos machadianos, 
escreveu: "Desta forma, a religião não se separava da literatura. (...) Machado de Assis aceitava a aproximação, porquanto este texto [poema intitulado Monte Alverne] sobre o pregador brasileiro finalizava uma série de estudos literários. (...) Suas crenças religiosas, embora vagas - tanto quanto as da maioria de seus companheiros - não eram menos sinceras" (MASSA apud QUEIROZ, 2008, p. 42).

Antes de mais nada, é necessário distinguir o Machado de Assis escritor e o Machado de Assis cidadão. Este último teve uma formação católica, foi coroinha da igreja da Lampadosa e teve aulas com o Pe. Antônio José Silveira Sarmento, que, segundo o próprio Machado de Assis, fora "um modesto preceptor e um agradável companheiro" (MACHADO DE ASSIS apud QUEIROZ, 2008, p.35). O escritor cresceu entre pessoas religiosas que o iniciaram na leitura dos textos sagrados, o que lhe angariou uma vasta, rica e profunda cultura bíblica. Segundo Marta de Senna (2003), no livro Alusão e zombaria: considerações sobre citações e referências na ficção de Machado de Assis, a obra machadiana é rica em numerosas citações bíblicas cuja utilização corresponde ao seu intuito de dessacralizar a palavra bíblica aplicando-a a situações profanas. Suas citações, conforme De Senna, aparecerão truncadas ou parcialmente transcritas ou até mesmo "significativamente interrompidas segundo a conveniência de seus narradores ardilosos..." (SENNA, 2003, p. 11). Arriscamos, pois, afirmar que ele conheceu as instituições religiosas de perto e, portanto, conforme ele escreveu, "onde ninguém mete o nariz, aí entra o meu, com a curiosidade estreita e aguda que descobre o encoberto" (MACHADO DE ASSIS, apud FARACO, 2004, p. 8). Ele também se expressou da seguinte forma: "Eu não sei dizer coisas fabuladas e impossíveis; mas as que me passam pelos olhos, as que os leitores podem ver e terão visto. Observo, ouço e escrevo" (MACHADO DE ASSIS apud PUJOL, 2007, p. 188).

Assim sendo, o autor observou o rumo que a Igreja Católica estava tomando em sua época e, com sutileza e ironia, foi pondo no papel a prática da fé católica pelo burguês carioca do século XIX, dessacralizando o compromisso cristão quanto à caridade, à bondade, ao desapego e à humildade, para barganhar com Deus o recebimento de uma graça.

Ainda neste raciocínio, através de seu estilo único, Machado de Assis vai abordar a religião não como um conjunto de dogmas ou de 
uma relação séria com o transcendente, mas como o ser humano lida com esse transcendente. Se formos contextualizar a época em que o escritor viveu, estávamos no Brasil do século XIX, em que Deus não é mais temido e passa a desempenhar um papel bastante secundário na vida das pessoas. O cristianismo, na opinião de Faoro (2001), não dizia mais respeito ao século XIX. Numa época em que predomina a Ciência com todos os ismos, o cristianismo não encontra recepção no homem e na mulher daquele século. Vive-se uma religiosidade de aparências, em que participar de um ato religioso significa ostentar uma falsa piedade, um pretexto para faltar a um compromisso enfadonho, e a conveniência é que dará o tom mais alto. Afinal, a opinião de Deus não conta mais, só a da sociedade.

\section{Resumo do conto}

Trata-se de uma conversa entre vários convidados que aguardam a sobremesa. A narração data de "mil setecentos e tantos" e, entre os comensais, estão o juiz-de-fora, chamado Sr. Veloso; Frei Bento, carmelita; o mestre-de-campo João Barbosa; dona Leonor, a anfitriã, e algumas senhoras:

Uma senhora de engenho, na Bahia, pelos anos de mil setecentos e tantos, tendo algumas pessoas íntimas à mesa, anunciou a um dos convivas, grande lambareiro, um certo doce particular. Ele quis logo saber o que era; a dona da casa chamou-lhe curioso. Não foi preciso mais; daí a pouco estavam todos discutindo a curiosidade, se era masculina ou feminina, e se a responsabilidade da perda do paraíso devia caber a Eva ou a Adão. As senhoras diziam que a Adão, os homens que a Eva, menos o juiz-de-fora, que não dizia nada, e Frei Bento, carmelita, que interrogado pela dona da casa, D. Leonor:

- Eu, senhora minha, toco viola, respondeu sorrindo; e não mentia, porque era insigne na viola e na harpa, não menos que na teologia.

Consultado, o juiz-de-fora respondeu que não havia matéria para opinião; porque as coisas no paraíso terrestre passaram-se de modo diferente do que está contado no primeiro livro do Pentateuco, que é apócrifo. Espanto geral, riso do carmelita que conhecia o juiz-de-fora como um dos mais piedosos sujeitos da cidade, e sabia que era também jovial e inventivo, e até amigo da pulha, uma vez que fosse curial e delicada; nas coisas graves, era gravíssimo. (MACHADO DE ASSIS, 2007, p. 359). 
Logo, o juiz-de-fora, referindo-se ao Gênesis, mais especificamente dizendo que o pentateuco é apócrifo (obra erroneamente atribuída a um autor ou cuja autoria não se pode provar) e que ele conhece o verdadeiro, afirma: “(...) Em primeiro lugar, não foi Deus que criou o mundo, foi o Diabo...” (MACHADO DE ASSIS, 2007, p. 360). A partir de então, o juiz-de-fora vai enumerando as "obras" do Tinhoso e as "obras" divinas. Conforme sua interpretação, o Tinhoso criou o mundo e coube a Deus "corrigir ou atenuar a obra" (ibid.). Se o Diabo, por exemplo, criou as trevas, Deus criou a luz. No segundo dia, nasceram as tempestades e os furacões, mas Deus contrapôs com as brisas da tarde. No terceiro, brotaram os vegetais, sem fruto e sem flor, espinhosos, e Deus criou as árvores frutíferas e os vegetais que "nutrem ou encantam". Após o Tinhoso ter criado abismos e cavernas, Deus fez o sol, a lua e as estrelas, no quarto dia. No quinto, surgiram os animais da terra, da água e do ar. No sexto dia, o Tinhoso criou o homem e a mulher, ambos sem alma e a quem Deus atribuiu uma alma e sentimentos puros e nobres. O casal é levado ao jardim do Éden e proibido de comer o fruto da árvore do Bem e do Mal:

Adão e Eva ouviram submissos; e ficando sós, olharam um para o outro, admirados; não pareciam os mesmos. Eva, antes que Deus lhe infundisse os bons sentimentos, cogitava de armar um laço a Adão, e Adão tinha ímpetos de espancá-la. Agora, porém, embebiam-se na contemplação um do outro, ou na vista da natureza, que era esplêndida. Nunca até então viram ares tão puros, nem águas tão frescas, nem flores tão lindas e cheirosas, nem o sol tinha para nenhuma outra parte as mesmas torrentes de claridade. E dando as mãos percorreram tudo, a rir muito, nos primeiros dias, porque até então não sabiam rir. Não tinham a sensação do tempo. Não sentiam o peso da ociosidade; viviam da contemplação. De tarde iam ver morrer o sol e nascer a lua, e contar as estrelas, e raramente chegavam a mil, dava-lhes o sono e dormiam como dois anjos. (MACHADO DE ASSIS, 2007, p.361).

O Tinhoso, evidentemente, não gosta do que vê e ordenou à serpente que convencesse o casal a comer do fruto proibido. Todavia, quando a serpente enumerou para Eva as vantagens que ela e Adão aufeririam se comessem o fruto - conhecimento da origem das coisas e da vida, o enigma da vida e o resplendor dos tempos - Eva recusou a oferta. 
Adão chega logo em seguida e também recusa a proposta da serpente. Deus, a fim de recompensar o casal pela sua força de caráter, envia o anjo Gabriel para buscar Adão e Eva e levá-los ao Paraíso.

Terminada a narração, todos se entreolham surpresos e o juiz-de-fora, após ser perguntado se o que ele acabara de contar era verídico, responde que nada daquilo acontecera e que se tivesse ocorrido, eles não estariam sentados à mesa, saboreando o doce.

\section{Inversão da ordem estabelecida}

Com base, pois, no fato de que Tillich escreveu que "a essência da Bíblia é o testemunho de experiências e encontros", estendemos esse conceito ao modo como Machado de Assis trabalhou a história da origem do mundo por meio de recursos, digamos, pouco convencionais. Se não, vejamos:

A causa principal do espanto provocado nos comensais e no leitor reside na inversão que Machado de Assis realiza através da ironia, a qual significa deslocamento de sentido. Aliado a esse deslocamento, temos o elemento sério-cômico (BAKHTIN apud OLIVEIRA, 2000), que faz parte da sátira menipeia. Esta se vincula às diferentes modalidades do folclore carnavalesco. E em que consiste o carnaval? Na inversão do mundo sério e oficial (no conto, a doutrina da Igreja Católica). Assim sendo, a imagem e a palavra mostram a realidade diferente do que os discursos oficiais apregoam. Com isso, Machado de Assis derruba a racionalidade, o dogmatismo, a seriedade.

A sátira menipeia, que, com o diálogo socrático, os simpósios e a poesia bucólica, constituem o gênero sério-cômico, se fundamenta na livre fantasia (cf. OLIVEIRA, 2000) e dará um tratamento cínico ao objeto. No conto, o cinismo se dá, por exemplo, com a fala do juiz-de-fora, que comenta: "Pensando bem, creio que nada disso aconteceu; mas também, D. Leonor, se tivesse acontecido, não estaríamos aqui saboreando este doce, que está, na verdade, uma coisa primorosa. É ainda aquela sua antiga doceira de Itapagibe?"

Ao desviar a vida do cotidiano (um almoço em que os comensais aguardam a sobremesa), Machado de Assis coloca os personagens diante de conceitos que foram, através do riso machadiano, "profana- 
dos". Entretanto, não nos limitemos a ver no conto uma transgressão ao convencional, ao estabelecido. O que propomos é que o escritor sugere que devemos desconfiar das coisas estabelecidas, categorizadas, estipuladas, como verdade única. Uma vez que, a bem dizer, um dos maiores questionamentos da existência é saber por que sofremos. Invertendo o sagrado, Machado de Assis colocou o episódio bíblico num contexto em que o Mal, que sempre nos aflige, é escolha nossa, pois nem temos a quem culpar, já que, aparentemente e num primeiro momento, o "bode expiatório", o primeiro casal, obedeceu a Deus. O sagrado (Gênesis) se mistura ao profano (doce de Itapagibe; almoço; fala do Frei Bento: "Eu, senhora minha, toco viola, respondeu sorrindo; e não mentia, porque era insigne na viola e na harpa, não menos que na teologia") e uma vez que "foi o Diabo que criou o mundo" coube a Deus somente o papel de corrigir ou atenuar a obra.

Apesar de, certo modo, Machado de Assis inverter a ordem estabelecida, ele o faz através do elemento cômico, cheio de familiaridades com Eva ("Eva apareceu daí a pouco, caminhando sozinha, esbelta, com a segurança de uma rainha que sabe que ninguém lhe arrancará a coroa").

Com total liberdade, Machado de Assis "mexe" no fato bíblico, no imaginário do leitor, sem se importar com a veracidade estabelecida.

Especificamente no conto Adão e Eva, nossas reflexões teológicas e, por extensão sobre a condição humana, serão estimuladas pela carnavalização, pela paródia e pela sátira menipeia. Esta última, já mencionamos. Vejamos, resumidamente, como as duas primeiras funcionam dentro do texto.

Carnavalização: liga-se ao riso e à paródia. Como um conjunto de festejos que já existiam desde a Antiguidade grega, na Idade Média, o Carnaval e, por extensão, a carnavalização, vai inverter a ordem normal. E, mais especificamente no conto Adão e Eva, essa subversão da ordem se dará quando Machado de Assis inverteu a narrativa da criação do mundo: o Diabo criou o mundo e não Deus. Já que ocorre uma inversão de hierarquia, e o sagrado e o profano se misturam, vemos, por consequência, uma excentricidade, que se concentra no juiz-de-fora, que afirma que a história da criação do mundo não ocorreu conforme fora descrito no primeiro livro do Pentateuco. Junto a isso, temos a aproximação de elementos opostos (sagrado/profano;trevas/ 
luz; tempestades/brisas da tarde; temporal/secular). Do mesmo modo, advém a profanação, que se encarrega de inverter ou relativizar a distância dos elementos, para poder retirar ou criticar o poder dominante (cf. Bergamasco).

Paródia: Conforme Oliveira (2010), a paródia, que significa conto paralelo, constitui uma maneira de a linguagem voltar-se para si mesma. A paródia, consoante Sant'Anna (Sant'Anna apud Oliveira, 2010, p.76), provoca uma deformação, apresenta um caráter contestador, é descontínua, entre outros aspectos. Assim sendo, Machado de Assis fez uso da paródia para desviar-se do texto bíblico. Com humor e com pessimismo, mas sem dizer que o mundo é exclusivamente mau, Machado de Assis, perscrutando a alma humana, solta sua narrativa e permite que o leitor reflita teologicamente. A ironia sobeja: frei Bento toca viola; o juiz-de-fora é que vai dar outra versão sobre a história da criação do mundo e o Pentateuco é apócrifo, o que causa estranhamento.

Portanto, o autor, além de desconstruir todo um imaginário que a instituição oficial transmitiu, nos faz debruçar sobre um tema com o qual o ser humano sempre se deparou e para o qual nunca encontrou uma resposta que esgotasse o assunto: o Mal. E a maior desconstrução que Machado de Assis realizou no conto que ora estudamos é sugerir que o Mal existiu antes do Bem e que o Tinhoso começou a agir antes da atuação divina.

$\mathrm{O}$ escritor, e aqui referimo-nos à sua obra da segunda fase, ateve-se à análise da alma humana e, através de situações comuns, mas empregando uma linguagem por cuja forma Machado de Assis era obcecado, leva o leitor à reflexão. A natureza do ser humano e suas escolhas é que interessam ao escritor. O sentir e o comportamento de seus personagens funcionam como ponto de partida para as reflexões machadianas. $\mathrm{O}$ enfoque, a trama e o espaço são usados funcionalmente, a serviço de um tema teórico de uma doutrina, de uma ideia.

Contrariamente à religião ou até mesmo a certas correntes filosóficas, Machado de Assis não nos acena com a esperança, uma vez que a eterna contradição humana nos faz oscilar constantemente entre o Bem e o Mal. Machado de Assis tinha esperança? Não. Embora ele nunca tenha negado a Deus nem se declarado antirreligioso, dificilmente ele vai usar o verbo esperar na conotação de que ele tem certeza que 
Deus o proverá. A esperança é o "ainda não" e nosso escritor sempre achava que o ser humano ainda não tinha condições de superar seus vícios, cobiça, pecados, fraquezas.

O escritor carioca não se preocupou se deveria ter visto na Bíblia a formação do cânone, mas concentrou-se na maneira como, inicialmente, Adão e Eva se relacionam com Deus (submissão, ociosidade, contemplação) e, invertendo a ordem, com total liberdade, "mexe" no fato bíblico, no imaginário do leitor, sem se importar com a veracidade estabelecida.

Machado de Assis tem consciência do público que ele pretendia alcançar, isto é, ele levou em consideração a situação em que se encontra o destinatário da mensagem. E o que vivenciávamos no Brasil, na segunda metade do século XIX? Quais eram as formas científicas e artísticas, econômicas, políticas e éticas vigentes? Como as pessoas refletiam sobre sua existência? O Brasil de Machado de Assis caracterizava-se por divisões sociais muito rígidas, em que o indivíduo já nasce com seu futuro social predestinado pela origem, raça e possibilidade de frequentar escolas. A sociedade, de acordo com Alfredo Bosi, em $\mathrm{Ma}$ chado de Assis: o enigma do olhar (2007), era paternalista, e a mulher tenta ocupar um lugar melhor dentro desse paternalismo, o qual poderia ser obtido através do binômio "matrimônio" e "patrimônio" (BOSI, 2007, p.27). Já naquela época, a arte de disfarçar e de manipular já dava o tom das relações sociais; assim, Machado de Assis conviveu nesse ambiente, que só se diferenciava, na opinião de Bosi, quando surgiam homens de retidão moral como Joaquim Nabuco, Rui Barbosa, Luís Gama e Raul Pompéia. Fora isso, chamado por Bosi de "um moraliste sem ilusões" (Ibid., p.28), Machado de Assis não punha sua crença na rede de valores nem nos ideais democráticos ou republicanos. Seu olhar "filtrou matizes psicológicos de atores presos a suas ambições ora realizadas, ora frustradas" (Ibid., p.28). Para o escritor, a vida é um palco em que todos representam um papel. Esse papel, segundo Bosi, compreende um papel social, o qual possui consistência, e a alma humana, que, se colocando "aquém da cena pública" (Ibid., p. 102), é "dúbia e veleitária"(Id.).

Colocando-se estrategicamente distante das convenções culturais do seu tempo (cf. BOSI, 2007), Machado de Assis, ao trabalhar sua 
visão universalista sobre a espécie humana e o destino, não restringiu suas personagens à galeria de tipos locais que realistas e naturalistas criaram em suas obras de ficção. Avesso a qualquer tipo de "conversão", ele apenas foi sugerindo o que ele compreendia sobre a condição humana, deixando sempre o leitor livre para decidir-se a favor ou contra o que descrevia.

\section{Cultura, existência, condição humana}

Tillich acreditava que "o que existe de comum entre os seres humanos, independentemente da sua cultura, é a participação de todos na existência" (p. 26-27), e penso que o autor de Quincas Borba também tivesse a mesma visão, só que o demonstrava através da literatura, que também é uma forma de cultura e possibilita o vislumbre de realidades, de sons, cheiros e toques acrescidos à imaginação do leitor que "reelabora, em sua mente, a obra artística" (MANZATTO, 2011, p.87).

Consoante Tillich, a linguagem religiosa tradicional é a "origem das representações caricaturalizadas da religião" (TILLICH, 2009, p. 27), no que concordo, pois tudo parece convergir para uma visão piegas ou apologética do discurso cristão. Machado de Assis usou a linguagem religiosa de maneira invertida e, mesmo assim, permitiu que o(a) leitor(a) - caso desejasse - fizesse suas reflexões sobre religião, política, casamento, economia. Mesmo quando ele lança mão de um discurso tradicionalmente religioso, o faz com o objetivo de apontar o ridículo, a hipocrisia, o oportunismo de quem o profere.

A presença de todos na existência é que nos permite nos debruçar sobre a condição humana, permeada de finitude, do sagrado, da contingência, do acaso. Tillich faz uma profunda e inspiradora reflexão sobre a participação da religião na vida espiritual, em que coloca a questão da religião em dois lados: ou constitui, para alguns teólogos cristãos, um simples elemento criativo do espírito humano em vez de dom da revelação divina, ou algo que recebemos de fora. Por essa segunda abordagem, em nossa relação com Deus,é este que toma a iniciativa. No conto Adão e Eva, a relação com o Divino não é externa, mas parte de uma criação do narrador da história, descrito por Machado de Assis, que carnavaliza, isto é, inverte o evento descrito na Bíblia. 


\section{Considerações finais}

Neste breve estudo, procuramos unir a visão que Tillich tinha sobre a Bíblia, a qual é a soma das experiências e dos encontros que pessoas no Antigo Testamento e no Novo Testamento, com a abordagem que Machado de Assis fez no conto Adão e Eva, em que o escritor inverte a ordem e afirma que o Diabo criou o mundo e que o casal do Éden não comeu o fruto proibido.

Machado de Assis inverteu o imaginário e sugeriu que a religião é um dos aspectos do espírito humano e não uma função especial desse espírito. Ao mesmo tempo, por intermédio da literatura, a qual não tem como objetivo estabelecer verdades únicas e imutáveis, o escritor proporciona ao leitor a liberdade de decidir o que bem quiser. Ao mesmo tempo, ele levou em conta a situação em que se encontra o destinatário da mensagem. Evidentemente, não se trata de um pensamento premeditado sobre quem leria seu texto - talvez isso até ocorresse -, mas no sentido de que embora fosse cético quanto ao progresso científico que caracterizava o século 19, à eficácia dos "ismos" e às demais "proezas" do homem de seu tempo, o escritor não era indiferente à ideologia reinante, embora a utilizasse para expressar sua mais profunda descrença na condição humana.

A Literatura é considerada o meio pelo qual o ser humano é capaz de alçar seus voos mais livres e, portanto, permite ao leitor compreender melhor a si e o mundo sem ter que se prender a princípios que vão guiar seu mergulho no mundo da imaginação, das sensações, do sonho, da reflexão.

A paródia da criação do mundo, cujos autores são Deus e o Tinhoso no conto Adão e Eva, veio eivada de ironias (recurso preferido de Machado de Assis) e coloca logo no início a questão da culpa (tema tão caro às religiões cristãs) relativa à perda da inocência, ao cometimento do pecado original, ao início de todo sofrimento humano. Apesar do tom leve do texto, Machado de Assis vai dando seu recado: ao mostrar que o frei Bento e o juiz-de-fora não se pronunciam quanto a quem se mostrou mais curioso - Adão ou Eva -, está apontando para uma atitude omissa e dissimulada de pessoas que representam, respectivamente, Deus e a Justiça. Aqui, o autor já está criticando a Igreja e a Lei. O 
frei se refere ao juiz-de-fora como a pessoa mais piedosa, mas é este que vai lançar dúvidas sobre o texto bíblico.

Pontos em comum entre ele e o teólogo e filósofo Paul Tillich, poderia dizer que é a possibilidade de se vislumbrar a Bíblia como a soma de experiências e encontros de pessoas apontadas pelo pensador e a maneira como Machado de Assis trabalhou o encontro, conquanto invertido, do leitor para com a história das origens do mundo. Outro ponto é a questão das vivências culturais que, no caso do escritor, o modo como a religião católica permeava as crenças populares e as da elite.

$\mathrm{Na}$ verdade, percebemos que Machado de Assis nos mostra as reações humanas. As relações humanas não são harmoniosas: o Tinhoso tem inveja da bondade e felicidade do casal edênico, a serpente odeia o casal, que, no texto machadiano, obedece a Deus. Todavia, sabemos que o texto bíblico narra o contrário: Adão e Eva desobedecem a Deus, instauram o Inferno na terra e não mais o Paraíso, e o ser humano é condenado a todo tipo de sofrimento. Não obstante, ao escrever em seu conto que o casal obedeceu a Deus, Machado de Assis desconstrói a história da origem do mundo para, como último consolo, nos mostrar que, apesar de realmente ter ocorrido a desobediência à ordem divina, ainda é melhor estarmos vivos, saboreando o doce de dona Leonor, mesmo que a vida signifique dor, sofrimento, frustração.

Afinal, em Machado de Assis, nunca temos absoluta certeza de nada e só um tipo de explicação ou de elucidação não é recurso confiável.

\section{Referências bibliográficas}

ASSIS, M. de. 50 contos / Machado de Assis: seleção, introdução e notas de John Gledson. São Paulo: Companhia das Letras, 2007.

BAKHTIN, M. M. A cultura popular na Idade Média e no Renascimento: o contexto de François Rabelais. São Paulo: Hucitec, 1999.

BERGAMASCO, R. de M. Paródia e carnavalização: uma leitura do conto "Adão e Eva" de Machado de Assis. Uniletras. Disponível em http://www. revistas2.uepg.br/index.php/uniletras/article/view/2936/3032. Acesso em: 28 jan. 2018.

BOSI, A. O enigma do olhar. $4^{\text {a }}$ ed. São Paulo: Martins Fontes, 2007. 
FAORO, R. Machado de Assis: a pirâmide e o trapézio. São Paulo: Globo, 2001.

MANZATTO, A. Pequeno panorama de teologia e literatura. In: MARIANI, Ceci Baptista e VILHENA, Maria Angela (orgs.). Teologia e arte: expressões de transcendência, caminho de renovação. São Paulo: Paulinas, 2011. - (Coleção teologia na universidade).

OLIVEIRA, D. S. Considerações sobre a paródia bíblica da criação do mundo no conto machadiano “Adão e Eva". Disponível em: https://revistas.unasp.edu. br/acch/article/view/19. Acesso em: 28 jan. 2018.

QUEIROZ, M. E. Machado de Assis e a religião: considerações acerca da alma machadiana. Aparecida, SP: Ideias e Letras, 2008.

ROCHA, João Cézar de (org.). Múltiplo Machado: primeiro Colóquio Casa Dirce. Rio de Janeiro: EdUERJ, 2015.

SENNA, M. de. Alusão e zombaria: considerações sobre citações e referências na ficção de Machado de Assis. Rio de Janeiro: Fundação Casa de Rui Barbosa, 2003.

TILliCH, P. Teologia da Cultura. São Paulo: Fonte Editorial, 2009. 